\title{
Food Quality Research Basedon Various Image Processing Techniques
}

\author{
Anjali Rai, Arpitha V, Mahima M Varkhedi, Chethan K
}

\begin{abstract}
Quality analysis and inspection of different kind of foods based on various attributes using image processing. Different kind of foods are examined based on their physical characteristics such as size, colour, blob, shape and texture. Various methodologies are used for inspection as well as for detection of foods to identify and quantify the features based on mentioned characteristics. This technique helped in recognizing first-rate and healthy food that is to be released in markets. The main purpose of adopting this method is to include those specifications that could go unnoticed by naked eye. Also, inspection that is carried manually can be curtailed significantly thereby increasing the efficiency and reliability with better utilization of time.
\end{abstract}

Keywords: Food Quality, Image processing, Physical characteristics, Food Types.

\section{INTRODUCTION}

Food quality deals with various characteristics of food that is accepted by the consumers. The main objective of food quality revolves around providing the best service to the consumers. Consumers have a judicious approach, while selecting a product keeping in mind the health concerns. Besides ingredient quality, cleanliness also plays a major role in food processing to maintain hygiene in order to ensure safest possible food for the consumers.

Image processing is a technique that plays a vital role in the domain of food inspection. It enables to execute variety of preceding that are required in food quality check. Various softwares are used to carry out the operations one such familiar software used is MATLAB R2017b. With the help of which pre-processing of images can be done for securing the colour using RGB including computer vision methodology for quality prediction model for appearance. Thus, image processing in food industries facilitates the detection of problems, in analysing images of foods.

Good quality food production have a huge impact on agricultural industries. Agricultural industries always seek in the improvisation of the technologies for the enhancement in efficiency. As the production of good quality food goes up,

Revised Version Manuscript Received on August 19, 2019.

Anjali Rai,Department of Electronics and Communication Engineering, Vidyavardhaka College of Engineering, Mysuru, Karnataka 570002,India.(email:raianjalionline@gmail.com)

Arpitha V, Department of Electronics and Communication Engineering, Vidyavardhaka College of Engineering, Mysuru, Karnataka 570002,India.(email:arpithavsrp@gmail.com)

Mahima M Varkhedi, Department of Electronics and Communication Engineering, Vidyavardhaka College of Engineering, Mysuru, Karnataka 570002,India.(email:mvarkhedi@gmail.com)

Chethan K, Department of Electronics and Communication Engineering, Vidyavardhaka College of Engineering, Mysuru, Karnataka 570002,India.(email:chethank@vvce.ac.in) the demand in the market increases which categorises these food products as value added products and benefits the agricultural industries. Quality of food is also responsible for driving the service sector which again brings success in the agricultural industries.

\section{LITERATURE REVIEW \& RESULTS}

Patel et al [1] studied the rice quality based on its physical attributes, image processing technique was involved to extract and observe the various physical characteristics of rice. Pre-processing was done for capturing colours using RGB, shrinking morphological operations to ensure no two grains touch each other without disturbing the nobility of a single grain. Fuzzy logic is used for edge detection to estimate and detect the region of boundary of the grain. Measurement of the rice grain was done by using MATLAB $\mathrm{R} 2017 \mathrm{~b}$. The results obtained after the conduction of rice quality check are as shown in Table 1:

Table 1: Length and Area of the rice grains of different types as identified by the image processing techniques.

\begin{tabular}{|c|c|c|c|}
\hline $\begin{array}{c}\text { Axis } \\
\text { Length/ } \\
\text { Area }\end{array}$ & $\begin{array}{c}\text { Small } \\
\text { seeds }\end{array}$ & $\begin{array}{c}\text { Normal } \\
\text { seeds }\end{array}$ & $\begin{array}{c}\text { Long } \\
\text { seeds }\end{array}$ \\
\hline $\begin{array}{c}\text { Major } \\
\text { axis length }\end{array}$ & 9 & 26 & 5 \\
\hline $\begin{array}{c}\text { Minor } \\
\text { axis length }\end{array}$ & 7 & 31 & 2 \\
\hline Area & 11 & 26 & 3 \\
\hline
\end{tabular}

Shape, size and arrangement of sweet corn seeds was inspected in paper [2]. The measurements of size was done by measuring two end points, shape was investigated by the knowledge of symmetry of the sweet corn and to determine the arrangements of sweet corn seeds, the edges of the images are figured out by the technique of Laplacian of Gaussian. Combination of these technique fetched $90 \%$ accuracy in the inspection procedure.

In paper [3], the quality check of the coriander seeds was performed based on image morphological operation. The methods used for quality inspection includes image analysis, image processing. This enables evaluation and grading of quality of spice food industries via computer vision and image processing.

The average pedestal seed count: $84.9 \%$

Foreign dement count: $\quad 11.10 \%$

Total seed count: $\quad 4.0 \%$ 
Paper [4], classifies fruits based on their colour, size and blob to check their quality. Blob detection was used for the detection of defected fruits, thresholding used for colour detection and binary image developed for size detection. The fruit used was tomato and various observations are made. The green colour detection accuracy is $94.28 \%$ whereas the defected fruit detection is $90.0 \%$. Using this methodology, the efficiency and accuracy of the output increases with adequate amount of reduction in time.

In paper [5], sea foods are analysed based on the quality depending upon colour, texture, size, bone defects and smell. The method used is computer vision for quality check and prediction model for the appearance. Computer vision is featured giving the details about size, shape and texture. This approach reduces the time investment and increases the efficiency of the product in the market sector.

Inspection of the products using digital images for quality check is another approach for easy and effective identification of variety of features of the product [6]. The digital images are captured using the cameras with the sensors connected to the RGB grabber card. The product chosen for automatic inspection here is cookies. Total 14 cookies were presented by covering the entire range of fuzzy values for lightness, size and surface coverage. The standard rating for the accepting the cookie was 50 centimeters. Difference was observed in fuzzy inferences and average consumers that resulted as $41 \% \mathrm{v} / \mathrm{s} 43 \%$. The cookies were approved and accepted based on favorable texture signaled by the consumers which also dependent on baked colour in complimentary with more Choco chips.

In paper [7], assessment of quality of the Thai Rice Kernel is done using Digital Image processing. Thai Rice is used here and image processing algorithms are developed and applied on it to measure the Thai Rice Kernels. The system used flatbed scanner for the low cost quality check which resulted into rapid evaluation and improvised results. The main advantage behind the adoption of such technique is to save more time when compared to manual inspection.

Classification of foods depending upon signature based approach is done in paper [8]. The investigation was done on biscuits, which included computer vision based quality check. The signature based approach used, was for the identification of any kind of defects present while biscuits are manufactured such as cracking, over baking and colour testing. MATLAB image acquisition tool and MATLAB image processing tool with $480 \mathrm{~K}$ pixels web camera were used to carry out the test procedure. It was observed that the proposed methodology showed $73 \%$ accuracy eradicating fatigue and boredom of humans that affects the efficiency and loss in output and $75 \%$ accuracy hike by lighting system i.e., used to obtain surface texture details.

In paper [9], qualities of fruits and vegetables is assessed using Near Infrared Cameras. Fruits and vegetables were inspected using computerized systems and near infrared spectroscopy. Good quality fruits and vegetables are separated after being processed based on their acceptable physical attributes. This method is used for examination of qualities of fruits and vegetables with more accuracy and preferred objectives.
Rice granules are analysed using image processing and neural networks in paper [10]. Once the image is acquired detection and morphological operation are performed to carry out quantitative specification of the rice granules. The analysis took place on Basmati rice and they are further separated based on grades of granules. Neural network was helpful in classifying when no overlapping of granules took place and classified the dataset with accuracy of $96 \%$. The main objective for deploying this method is to increase the performance and decrease the time.

\section{CONCLUSION}

Various foods like rice, biscuits, cookies, fruits, vegetables, sweet corn seeds, coriander seeds and seafood were examined. The main idea was based on image processing and numerous methods were employed such as fuzzy method, computer vision for quality inspection, image analysis and processing thereby eliminating manual handling and increasing accuracy, efficiency and performance of the food industries. These methods showed respective intensities by acquiring $90 \%$ accuracy and efficiency in each field. With this objective time consumption is reduced and production is increased that improved the recognition features in different domains. The obtained results showed significant difference with generated proofs in all the areas where the tests are performed. These implementations in food industries reduces the complexity of grading problems. In future, with the help of computer vision technology we are planning to eradicate manual errors that leads to increase in the efficiency and production of quality food.

\section{ACKNOWLEDGEMENT}

The authors express gratitude towards the assistance provided by Dr. Nikesh V V, Accendere Knowledge Management Services Pvt Ltd for the expert advice

\section{REFERENCES}

1. N. Patel, H. Jayswal, and A. Thakkar, "Rice quality analysis based on physical attributes using image processing technique," RTEICT 2017 - 2nd IEEE Int Conf. Recent Trends Electron. Inf. Commun. Technol. Proc., vol. 2018-January, pp. 42-47, 2018.

2. M. Wattana, T. Phonarin, and U. Ketnork, "Quality Inspection of Size, Shape and Arrangement of Sweet Corn Seeds by Image Processing," Proc. - 17th IEEE/ACIS Int Conf. Comput. Inf. Sci. ICIS 2018, pp. 463-467, 2018.

3. R. R. Parmar, K. R. Jain, and C. K. Modi, "Image Morphological Operation Based Quality Analysis of Coriander Seed (Coriandrum Satavum L)," 2011 Int Conf. Emerg. Trends Networks Comput. Commun., pp. 482-486, 2011.

4. M. R. Satpute and S. M. Jagdale, "Automatic Fruit Quality Inspection System," 2016 Int. Conf. Inven. Comput. Technol., vol. 1, pp. 1-4.

5. X. Tao, H. Li, J. Lu, and X. Wang, "Computer Vision Technology for Seafood Quality Evaluation,” 2012 Int Conf. Comput. Sci. Serv. Syst., pp. 1888-1891, 2012.

6. V. Davidson, T. Chu, and J. Ryks, "Fuzzy Methods for Automated Inspection of Food Products,” pp. 2-6, 1999. 
7. P. Kongsawat, "Quality Assessment of Thai Rice Kernels Using Low Cost Digital Image Processing System,” 2018 Int. Work. Adv. Image Technol., pp. 1-4, 2018.

8. P. D. S. H. Gunawardane and P. T. R. Dabare, "A Signature Based Approach for Quality Checking of Biscuits," 2015 8th Int. Conf. Ubi-Media Comput., pp. 92-97, 2015.

9. D. Türker, "Yak Õ n K Õ z Õ lötesi Kamera ile Meyve ve Sebzelerin Kalite Ölçümü Quality Measurement of Fruits and Vegetables with Near Infrared Camera," pp. 1-4, 2017.

10. P. Neelamegam, S. Abirami, V. P. K, and R. V. S, "Analysis of rice granules using Image Processing and Neural Network," 2013 IEEE Conf. Inf. Commun. Technol., no. Ict, pp. 879-884, 2013. 